This document is published in:

Regional Science and Urban Economics, 2004, v. 34, n. 3, pp. 309-320

DOI: http://dx.doi.org/10.1016/S0166-0462(03)00042-5

(C) 2003 Elsevier B.V. All rights reserved 


\title{
Geographical specialisation in Spanish agriculture before and after integration in the European Union
}

\author{
Ricardo Mora, Carlos San Juan* \\ Universidad Carlos III de Madrid, Departamento de Economı 'a, Madrid, Spain
}

\begin{abstract}
This paper analyzes the evolution of agricultural product specialisation at the farm and county levels in Spain from 1979 to 1997. This period covers all the stages of the gradual implementation of the Common Agricultural Policy and the integration of the Spanish agriculture into the European Market. A multiple product version of Theil and Finizza's indices of segregation is used to decompose farm product specialisation into county specialisation with respect to the national level and farm specialisation within counties. Using a probit specification, we test whether changes in specialisation are driven by comparative advantage at regional level or have been policy induced. Our results confirm the existence of increasing county specialisation and highlight the fact that counties which were initially more specialised in export oriented products have shown the largest increase in specialisation.
\end{abstract}

JEL classification: C43; Q12; Q18; R32

Keywords: Spatial product specialisation; Comparative advantage; Common Agricultural Policy

\section{Introduction}

Rural landscapes evolve in conjunction with regional specialisation shifts. Since environmental and productive objectives are key issues in current international discussions on agricultural policy reform, the analysis of the forces affecting geographical specialisation trends is central to evaluating the impact of policy intervention in agricultural markets.

Before entry in the European Community in 1986, agricultural policy in Spain provided lower levels of protection for farmers than did the Common Agricultural Policy (CAP).

\footnotetext{
* Corresponding author. Tel.: +34-91-624-9577; fax: +34-91-624-9875.

E-mail addresses: ricmora@eco.uc3m.es (R. Mora), csj@eco.uc3m.es (C. San Juan).
} 
Subsidies as a percentage of the value of total production, which were just 2.3 percent in 1980, jumped to 15.1 percent in 1997. Foreseeing the changes, the Spanish government increased guaranteed prices before entry so that price convergence for most products started in 1984 under CAP intervention. The official transition period started in 1986 and lasted until 1992. During those years, intervention prices and market regulations progressively approached the CAP's Common Market Organization (CMO) prices and regulations. By 1993, the Spanish farming industry was fully integrated in the CAP's $\mathrm{CMO}$ and enjoyed free access to the European food market.

The aim of the paper is to quantify the joint effect of CAP and market enlargement on Spain's farm specialisation. As any positive theory of trade will predict, market liberalisation increases competitive exports and their relative prices. ${ }^{1}$ However, integration into the European market and implementation of the CAP may produce opposing forces in the process of product specialisation. On the one hand, integration in competitive markets should lead to greater geographical specialisation in crops for those regions which enjoy a comparative advantage based on factor endowments such as land and weather conditions. On the other hand, the CAP introduces two main distortions limiting efficient specialisation: intervention prices and set-aside programs. Spain's entry into the European Communities raised prices both for crops for which the country enjoyed comparative advantage, such as vegetables and fruits, as well as for crops that benefited from the CAP policy. Thus, a priori, the overall result on specialisation is not clear.

This paper contributes to the empirical literature on agricultural specialisation in two ways. First, previous studies have focused on regional specialisation, i.e. how agricultural production differs across regions within a country. The implicit assumption behind this restriction is that farm specialisation within a county, i.e. how agricultural production differs across farms within a county, is relatively low within homogeneous regions (Peterson, 1995; Hubbell and Welsh, 1998). In the Spanish case, there is evidence of important differences between inland and Mediterranean agriculture (Garcia Alvarez Coque et al., 1999; Mora and San Juan, 2002), but there are no previous studies dealing with crop specialisation at the farm level within narrow geographical units such as counties. In this paper, a general version of the informational measure of segregation proposed by Theil and Finizza (1971) is used to study crop specialisation. A fundamental advantage of this index here is that farm specialisation with respect to the country's crop distribution is broken down into two terms. The first term can be defined as county specialisation, and measures the extent to which the production distribution at county level differs from the national level. The second term can be defined as farm specialisation within counties, and measures the differences between farm and county averages. After carrying out this decomposition it is a straightforward matter to test the evolution of county (or regional) specialisation as opposed to farm specialisation within counties.

Second, the underlying factors affecting increases in both county and within-county farm specialisation are analysed using a parametric specification. The hypothesis being

\footnotetext{
${ }^{1}$ For a short survey of main trade theories see Jones and Neary (1984). More recently, Overman et al. (2001) survey the empirical literature on the economic geography on trade flows, factor prices, and the location of production in imperfectly competitive industries with market linkages, knowledge spillovers and labour market externalities. Our approach modelling agricultural trade is nearest to the modified Heckscher Ohlin Vanek model as in Trefler (1993).
} 
Agricultural characteristics in Spain by major crop

\begin{tabular}{llllcr}
\hline & $\begin{array}{l}\text { Prices } \\
\text { changes } \\
1979: 1997\end{array}$ & $\begin{array}{l}\text { Exports } \\
\text { shares }\end{array}$ & $\begin{array}{l}\text { PSE } \\
1979: 1986\end{array}$ & $\begin{array}{l}\text { Produce } \\
\text { shares }\end{array}$ & $\begin{array}{l}\text { Produce } \\
\text { shares } \\
1983\end{array}$ \\
\hline Grain cereals & 4.10 & 1.50 & 33.22 & 34.01 & 21.92 \\
Livestock production & 7.26 & 1.06 & 37.00 & 19.43 & 25.95 \\
Industrial crops & 4.35 & 2.54 & 52.41 & 10.58 & 9.79 \\
Field crop & 5.16 & 2.45 & 0.00 & 9.69 & 8.55 \\
Vegetables & 6.93 & 19.93 & 4.18 & 7.58 & 14.56 \\
Fruits & 5.37 & 48.17 & 4.18 & 6.30 & 6.54 \\
Vineyard & 15.77 & 29.57 & 4.97 & 4.42 & 5.24 \\
Olive grove & 7.73 & 30.78 & 7.79 & 3.40 & 4.03 \\
Potatoes & 4.07 & 2.80 & 0.00 & 3.23 & 2.90 \\
Dried pulses & 5.10 & 4.20 & 0.00 & 1.35 & 0.51 \\
Total & & & & 100.00 & 100.00 \\
\hline
\end{tabular}

Note: All values are expressed in percentage terms. Data on prices come from the Spanish agricultural survey prepared by the Ministry of Agriculture. Prices changes were computed using interannual growth rates of Fisher indices. Exports are the Spanish average share of exports within each of the crops in the 1979:1983 period from MEH (1979 1997) and own calculations. PSE shows the 1979:1986 average Producer Subsidies Equivalents (PSE) obtained from OECD (1994) and own calculations. PSEs are measured as the percentage value per unit of output of transfers to farmers generated by agricultural policy.

tested is that initial county specialisation in export-oriented products has led to higher county specialisation, as the theory of economic integration would suggest. Furthermore, the effects of generous CAP support are studied for both county specialisation and farm specialisation within counties as changes in specialisation due to market intervention can arise not only between counties but also within counties.

The rest of the paper is organized as follows: Section 2 of the paper discusses the sources of product specialisation change at the farm and county level. In Section 3, we present the methodological framework which is then applied to the Spanish case in Section 4. Finally, Section 5 provides some concluding comments.

\section{The sources of product specialisation change at the farm level}

Multi-product farms maximise profits by choosing production levels for each crop. Factors affecting this decision include price differentials so that, in the long run, trends in relative prices will have an important effect on the composition of production across farms. In Spain, these trends have been markedly different across products in the period under study, as shown for ten different crops in Table $1 .^{2}$ A positive correlation of 0.31 is found between crop price increases and changes in national shares. By far, vegetables (an export-oriented product) and livestock production (strongly supported by the CAP) experienced the two largest increases in their shares of total output between 1979 and

\footnotetext{
2 The data comes from the Spanish agricultural survey prepared by the Ministry of Agriculture. See Section 4 below for a more detailed description of the original data. Price changes were computed using interannual growth rates of Fisher indices.
} 
1997. Although local factors such as weather and soil conditions limit the extent of these trends ${ }^{3}$, it may be argued that a driving mechanism in product specialisation at the national level has been the long-term evolution of crop prices.

Price trends reflect, amongst other factors, both the opening of the European market for Spain's agricultural sector and the implementation of price intervention within the CAP. The largest increases in prices have taken place in crops for which the country had an initial comparative advantage. As mentioned earlier, integration in competitive markets should lead to greater geographical specialisation in crops for regions with a comparative advantage based on factors such as land and weather conditions. The second column of Table 1 shows the average share of exports within each of the crops in the 1979:1983 period. ${ }^{4}$ Before integration in the European market, Spain exported a large share of vegetables, fruits, wine and olive oil to Europe. During the process of integration, price increases in those four categories averaged 8.4 percentage points, well above the 5.1 national average.

At the same time, livestock production, which receives CAP support, also witnessed strong price increases. High intervention prices should lead to surpluses in crops that benefit from the policies. The effect on regional specialisation is ambiguous since protected surpluses may be found in all regions, not only in those with initially high levels of production. In the third column of Table 1 we report average Producer Subsidies Equivalents (PSE) for the period 1979:1986 in the 10-member European Community which reflects the level of initial CAP intervention. ${ }^{5}$ Grain cereals, livestock production and industrial crops were strongly supported at the time. Finally, potatoes, which were neither export-oriented nor eligible for policy support, experienced the lowest change in prices. This suggests that both market enlargement and the implementation of the CAP have potentially led to important shifts in specialisation driven by changes in relative prices.

Another factor which has potentially affected the change in product specialisation is the set-aside program introduced after 1992. CAP's acknowledged shortcomings ${ }^{6}$ have triggered reforms, the most important one being that of 1992. It consisted of an attempt to partly substitute market price support with direct payments, the objective being to reduce surpluses. The new policy was mainly implemented in cereals where direct payments have since been based on historical use of land and yields and have been operated in conjunction with a set-aside requirement and a reduction in the support price. Beyond a certain farm size, farmers would have to set aside a portion of their arable land in order to qualify for area payments. Farmers would nonetheless be entitled to grow crops for industrial use on set-aside land. The effects of these arrangements on farm specialisation, with respect to both county and national patterns, is clearly an empirical issue, as

${ }^{3}$ Livestock production is concentrated in the northern regions whilst vegetables and fruits are mainly concentrated in the southern and eastern regions.

${ }^{4}$ Figures are obtained from the Spanish Ministry of Economy publication MEH (1979 1997) and own calculations.

${ }^{5}$ Figures are obtained from OECD (1994) and own calculations. PSEs are measured as the percentage value per unit of output of transfers to farmers generated by agricultural policy.

${ }^{6}$ See, for example, Messerlin (2001) and Weyerbrock (1998). 
farms are free to choose crop distribution on the merits of price and compensation payments by either concentrating or diversifying production and can still meet their setaside obligations. The effects of this program are concentrated in areas that qualify for compensation payments, i.e. those with high historical land use for cereals.

Two internal factors may also have affected specialisation between and within counties. First, a strong increase in the regional presence of the food processing industry can increase local prices and thus create an incentive to specialise in crops to supply the new manufacturing plants in the region. Second, farm size varies across large regions in Spain, with the largest concentration of small farms in the Northwest area. During the period under study, the number of small farms has steadily declined. This structural change may also have had a regional effect on the level of specialisation, since the initial proportion of small farms varied by region.

We expect, a priori, that some of these factors are relevant at the county level, such as market enlargement, whilst others, such as set-aside programs or the change in the proportion of small farms, may be important at both levels. ${ }^{7}$ In order to explore these issues, a multi-product version of Theil and Finizza's index of segregation is presented in the next section. The index and its evolution over time decompose farm specialisation into county and within-county specialisation, so that an assessment of the effects of the factors that have contributed most to specialisation can be carried out.

\section{Regional versus farm specialisation}

Product concentration can be analysed by looking at the entropy measure for the national agricultural production at any period of time:

$$
\mathrm{E}=\Sigma_{i}\left(Y_{i} / Y\right) \log _{N}\left(\left(Y_{i} / Y\right)^{1}\right)
$$

Here $Y_{i}$ is the national output of crop $i, Y$ is total production, $N$ is the number of crops, and $\log _{N}$ is the logarithm in base $N$. This index measures crop specialisation at the national level and lies between 0 and 1 . If national production is equally distributed across crops, then $E$ takes its maximum value $(E=1)$. If all production is concentrated in one product, then $E$ takes its minimum value $(E=0)$. Eq. (1) can also be applied within each county. In the following, we will denote counties by $r$ :

$$
E_{r}=\Sigma_{i}\left(Y_{i r} / Y_{r}\right) \log _{N}\left(\left(Y_{i r} / Y_{r}\right)^{1}\right)
$$

The set of indexes $\left\{E_{r}\right\}$ can be aggregated to construct an overall index of county product concentration, $\hat{E}_{r}=\Sigma_{r}\left(Y_{r} / Y\right) E_{r}$. In order to analyse to what extent the production pattern

\footnotetext{
7 Some agricultural inputs, like weather and soil conditions, are geographically fixed and show little variance within counties. Differences in the distribution of these factors map into a pattern of geographical comparative advantages. Thus, integration in competitive markets should lead to county specialisation. In a similar vein, Capt and Schmitt (2000) argue that the forces at work in the location of agricultural production operate schematically on two separate scales. In addition to the traditional comparative advantages modelled at regional level, the influence of urban centres remains important for nearby agriculture and land rent (von Thunen's model) is still a driving force for the location of agricultural production around cities.
} 
in a county differs from the national pattern, Theil and Finizza's measure of segregation is easily extended to more than two products. In information theory,

$$
I_{r}=\sum_{i}\left(Y_{i r} / Y_{r}\right) \log _{N}\left(\left(Y_{i r} / Y_{r}\right) /\left(Y_{i} / Y\right)\right)
$$

is known as the expected information of the message that transforms the proportions $\left\{\left(Y_{i} / Y\right)\right\}_{i}$ to a second set of proportions $\left\{\left(Y_{i r} / Y_{r}\right)\right\}_{i}$. The value $I_{r}$ is zero when the two sets are identical; it takes larger values when the two sets differ. Theil and Finizza (1971) show that the weighted average of the value $I_{r}, \hat{I}_{r}=\Sigma_{r}\left(Y_{r} / Y\right) I_{r}$, is bounded by 1 as it accounts for the difference between the national entropy and the weighted average of county entropy measures:

$$
\hat{I}_{r}=E-\hat{E}_{r}
$$

Our objective is to analyse the extent to which farms specialise with respect to the county and the national pattern. Let $Y_{\text {irf }}$ be the output of crop $i$ at farm $f$ from county $r$ so that $Y_{i r}=\Sigma_{f \subset r} Y_{i r f}$ and $Y_{r f}=\Sigma_{i} Y_{i r f}$. A bounded measure of total farm specialisation from the national pattern is $\hat{I}_{f}=\Sigma_{f}\left(Y_{r f} / Y\right) I_{f}$ where

$$
I_{f}=\Sigma_{i}\left(Y_{i r f} / Y_{r f}\right) \log _{N}\left(\left(Y_{i r f} / Y_{r f}\right) /\left(Y_{i} / Y\right)\right)
$$

Alternatively, farm $f$ specialisation within county $r$ can be defined as

$$
I_{r f}=\Sigma_{i}\left(Y_{i r f} / Y_{r f}\right) \log _{N}\left(\left(Y_{i r f} / Y_{r f}\right) /\left(Y_{i r} / Y_{r}\right)\right)
$$

An index of within-county specialisation at county level aggregates $I_{r f}$ over farms in county $r$ :

$$
\ddot{I}_{r f}=\Sigma_{f \subset r}\left(Y_{r f} / Y_{r}\right) I_{r f}
$$

Finally, a national index of within-county specialisation can be obtained by aggregating $\ddot{I}_{r f}$ over counties:

$$
\hat{I}_{r f}=\Sigma_{r}\left(Y_{r} / Y\right) \ddot{I}_{r f}
$$

Then, it can be shown that: ${ }^{8}$

$$
\hat{I}_{f}=\hat{I}_{r}+\hat{I}_{r f}
$$

Farm specialisation is divided into two components. The first term measures differences across counties with respect to the national standard. The second term measures withincounty farm specialisation. In order to study the sources of specialisation change, we can exploit the additive properties of the indexes. Using Eq. (9), the change in overall farm

8 This is an extension of the well-known decomposition of Theil's index of concentration to Theil and Finizza's index of segregation. See Mora and Ruiz-Castillo (2000) for a proof of this extension. 
specialisation, $\nabla \hat{\mathrm{I}}_{f}=\hat{\mathrm{I}}_{f}^{97}-\hat{\mathrm{I}}_{f}^{79}$, can be decomposed in three components within each county:

$$
\nabla \hat{I}_{f}=\Sigma_{r}\left[\left(Y_{r} / Y\right)^{t} \nabla I_{r}+\left(Y_{r} / Y\right)^{t} \nabla \ddot{I}_{r f}+\nabla\left(Y_{r} / Y\right)\left(I_{r}+\ddot{I}_{r f}\right)^{s}\right]
$$

where $t=79$ and $s=97$ if indices are weighted by production shares at the beginning of the period, or $t=97$ and $s=79$ if weights are taken from the end of the period. In the next section, the decomposition (9) is computed for the Spanish agricultural sector. Then, the two alternative decompositions from Eq. (10) are obtained. Finally, dummy variables for positive changes in $\nabla I_{r}, \nabla \ddot{I}_{r f}$ and $\nabla\left(Y_{r} / Y\right)$ are calculated and probit estimations carried out to analyse the effects of market enlargement and policy interventions on specialisation.

\section{The decomposition of Spanish farm specialisation}

\subsection{The data set}

The Red Contable Agraria Nacional (RECAN), an annual national survey prepared by the Spanish Ministry of Agriculture, has been part of the European Farm Accounting Data Network since 1985. The questionnaire is filled in by accountancy agencies that collect information directly from the commercial farms. ${ }^{9}$

Every year, the survey provides information on crop production for around 7000 farms and 70 crops. Because of sample size, crop information is aggregated into ten major agricultural products. ${ }^{10}$ Farm location is reported only at provincial level, a geographical unit that includes several agrarian areas for most provinces. However, it is possible to combine this information with altitude above sea level and create three areas within each province which, given Spain's geographical characteristics, are approximately homogeneous in weather and soil conditions. The high region includes all farms located 600 meters above sea level in the same province. The intermediate region comprises farms located between 300 and 600 meters above sea level. Finally, the low region includes all farms lower than 300 meters above sea level. After interaction of the province code with the altitude dummy variable, the country can be split into 115 different small geographical units. For reasons of brevity, we will refer to these small geographical units as 'counties'. The average sample of farms per county and year is 70 , a relatively small number. A potential shortcoming of computing specialisation indices with small samples is that random allocations of farms in the sample may lead to high levels of county specialisation measurements purely by chance. We address this problem in two ways. First, we aggregate all years into four periods which coincide with the relevant stages of the Spanish integration

9 A commercial farm is defined as a farm that is large enough to provide a main activity for the farmer and a level of income sufficient to support his or her family. In order to be classified as commercial, a farm must exceed a minimum economic size of 2400 euros.

10 These are livestock production, field crop, grain cereals, vineyard, potatoes, industrial crops, vegetables, fruits, dried pulses, and olive grove. 
into the EU. ${ }^{11}$ Second, we use bootstrap techniques to compute standard errors so that we can assess the degree of accuracy in our specialisation indexes, as in Deutsch et al. (1994) and Boisso et al. (1994).

\subsection{Variable definitions}

In order to analyse the effects of market enlargement, an index of initial comparative advantage is computed by county. Exports Potential, (EP), is defined as the expected percentage of exports over total production based on crop production levels in the first period of the sample by county:

$$
\mathrm{EP}_{r}=\sum_{i} x_{i}\left(Y_{i r} / Y_{r}\right)
$$

where $x_{i}$ is the share of exports on total national production for crop $i$. A county that is specialised in export-oriented products during the first period at national level will have a high value for $\mathrm{EP}_{r}$.

Concerning the effect on specialisation via CAP intervention, the propensity to receive support from the Common Agricultural Policy by county $r$, is included. Subsidy Propensity $\left(S P_{r}\right)$, is defined as:

$$
\mathrm{SP}_{r}=\sum_{i} s_{i}\left(Y_{i r} / Y_{r}\right)
$$

Here $s_{i}$ is the average producer subsidy equivalent due to the CAP during the period 1979:1986 for crop $i$. A county that is initially specialised in heavily supported products in the European Community will have a higher value for $\mathrm{SP}_{r}$.

The initial percentage of cereal land use in the county, $S A$, is included to measure the potential for set-aside after 1992.

To capture the effect of changes in the food processing industry, the econometric specification includes the number of new food processing plants, NFPP, at a provincial level. This variable covers the entire period and is taken from the Registro de Estable cimientos Industriales, a registry of industrial establishments provided by the Spanish Ministry of Industry. ${ }^{12}$ Finally, we use census data from the Censo Agrario to compute the overall percentage change in the number of small farms at province level, $S F$, between 1979 and 1997 to control for the process of land concentration.

11 These are: From 1979 until 1983 (pre-integration); from 1984 until 1987 (policy convergence); from 1988 until 1992 (integration); and from 1993 until 1997 (after CAP reform).

12 Two econometric concerns arise from the use of this variable. First, a potential problem of endogeneity appears since industrial plants may choose to locate near the crop production centres. We carried out a test for weak exogeneity initially proposed by Engle (1984), pp.815 816, for each type of crop and could not reject the null, that decision to locate new food processing plants are weakly exogenous to the evolution of crop production. Second, the use of provincial level on new plants, due to the lack of county data, could potentially lead to aggregation bias. However, in studies of geographical linkages, production and location decisions are inversely related to the distance to neighbouring markets (Hanson, 1998, and Desmet and Fafchamps, 2000). Choosing the provincial level, a higher geographical unit, captures this feature in a simple way. 
Table 2

County versus farm specialisation

\begin{tabular}{llll}
\hline & $\hat{I}_{r}$ & $\hat{I}_{r f}$ & $\hat{I}_{r}+\hat{I}_{r f} \quad \hat{I}_{f}$ \\
\hline 1979:1983 (pre-integration) & 27.87 & 29.95 & 57.83 \\
& $(0.86)$ & $(1.47)$ & $(2.31)$ \\
1984:1987 (policy convergence) & 34.36 & 25.01 & 59.38 \\
& $(0.57)$ & $(2.73)$ & $(3.24)$ \\
1988:1992 (integration) & 35.21 & 27.56 & 62.77 \\
& $(0.67)$ & $(1.52)$ & $(2.16)$ \\
$1993: 1997$ (after CAP reform) & 40.03 & 27.59 & 67.62 \\
& $(0.60)$ & $(1.39)$ & $(1.95)$ \\
\hline
\end{tabular}

Note: Bootstrapped standard errors with 1000 simulations in parenthesis.

$\hat{I}_{r} \quad \Sigma_{r}\left(Y_{r} / Y\right)\left[\Sigma_{i}\left(Y_{i r} / Y_{r}\right) \log _{10}\left(\left(Y_{i r} / Y_{r}\right) /\left(Y_{i} / Y\right)\right)\right]$ (County specialisation); $\hat{I}_{r f} \quad \Sigma_{r} \Sigma_{f}\left(Y_{r f} / Y\right)\left[\Sigma_{i}\left(Y_{i r f} / Y_{r f}\right) \log _{10}\right.$ $\left.\left(\left(Y_{i r f} / Y_{r f}\right) /\left(Y_{i r} / Y_{r}\right)\right)\right]$ (Farm specialisation within counties); $\hat{I}_{f} \quad \hat{I}_{r}+\hat{I}_{r f}$ (Total farm specialisation).

\subsection{Empirical results}

In this section, the methodology presented in Section 3 is applied to the Spanish farmlevel agricultural data. The results of the decomposition (9) are presented in Table 2. Bootstrapped standard errors were obtained with 1000 replications of the empirical sample with replacement.

Total farm specialisation has gone up $17 \%$, from 57.8 to 67.6 . The decomposition into a between and a within component shows that all of this increase is attributable to the increase in county specialisation, from 27.9 in the 1979:1983 period to 40.0 index points in the 1993:1997 years. Farm specialisation within counties has, if anything, decreased at the national level, starting from 30.0 in 1979:1983 and falling to 27.6 during 1993:1997. However, we cannot reject the hypothesis that farm specialisation within counties has remained constant.

Table 3 shows decompositions obtained by applying Eq. (10). Around 58\% of the increase in the overall specialisation index results from increases in production in counties with high initial specialisation levels. This result is robust to the choice of the reference period in the decomposition. The effect of regional specialisation is also unambiguous and positive, whilst the effect of within-county specialisation depends on the period of reference. When the changes in within-county specialisation, $\nabla \ddot{I}_{r f}$, are

Table 3

The decomposition of change in specialisation

\begin{tabular}{lllllll}
\hline & & $\Sigma_{r}\left(Y_{r} / Y\right)^{t} \nabla I_{r}$ & $\Sigma_{r}\left(Y_{r} / Y\right)^{t} \nabla \ddot{I}_{r f}$ & $\sum_{r} \nabla\left(Y_{r} / Y\right)\left(I_{r}+\ddot{I}_{f r f}\right)^{s}$ & $\nabla \hat{I}_{f}$ \\
\hline$t$ & $1979: 1983, s$ & $1993: 1997$ & 6.61 & 2.41 & 5.59 & $\mathbf{9 . 7 9}$ \\
$t$ & $1993: 1997, s$ & $1979: 1983$ & 1.79 & 2.19 & 5.82 & $\mathbf{9 . 7 9}$ \\
\hline
\end{tabular}

Note: $\Sigma_{r}\left(Y_{r} / Y\right)^{t} \nabla I_{r}$ : Changes in specialisation from changes in county specialisation. $\Sigma_{r}\left(Y_{r} / Y\right)^{t} \nabla \ddot{I}_{r f}$ : Changes in specialisation from changes in farm specialisation within counties, where

$$
\left.\ddot{I}_{r f}=\Sigma_{f \subset r}\left(Y_{r f} / Y_{r}\right) I_{r f}\right)
$$

$\sum_{r} \nabla\left(Y_{r} / Y\right)\left(I_{r}+\ddot{I}_{r f}\right)^{s}$ : Changes in specialisation from changes in regional output shares. $\nabla \hat{I}_{f} \quad \sum_{r}\left[\left(Y_{r} / Y\right)^{t} \nabla I_{r}\right.$ $\left.+\left(Y_{r} / Y\right)^{t} \nabla \ddot{I}_{r f}+\nabla\left(Y_{r} / Y\right)\left(I_{r}+\ddot{I}_{r f}\right)^{s}\right]:$ Changes in total farm specialisation. 
Table 4

The sources of change in specialisation between 1979 and 1997

\begin{tabular}{|c|c|c|c|c|c|c|}
\hline & \multicolumn{2}{|c|}{$\nabla\left(Y_{r} / Y\right)>0$} & \multicolumn{2}{|l|}{$\nabla I_{r}>0$} & \multicolumn{2}{|l|}{$\nabla \ddot{I}_{r f}>0$} \\
\hline & (1) & (2) & (3) & (4) & (5) & (6) \\
\hline Exports potential & 0.77 & 0.93 & $1.51 * *$ & $1.30 * *$ & 0.002 & 0.14 \\
\hline Subsidy propensity & $1.89 * *$ & $1.82 * *$ & 0.61 & 0.38 & 0.92 & 1.17 \\
\hline Set aside $/ 100$ & 0.32 & 0.32 & $0.62 * * *$ & $0.63 * * *$ & 0.31 & $0.36^{*}$ \\
\hline New food-processing plants/10 & 0.26 & & 0.14 & & 0.002 & \\
\hline Small farms $/ 100$ & 0.24 & & 0.21 & & 0.11 & \\
\hline Pseudo- $R^{2}$ & 0.15 & 0.13 & 0.11 & 0.10 & 0.04 & 0.03 \\
\hline
\end{tabular}

Note: Probit estimates of the change in the probability for an infinitesimal change in each independent variable. The number of observations is $N \quad 115$. The Pseudo- $R^{2}$ goodness-of-fit measure is defined as $1 \quad L_{1} / L_{0}$ where $L_{0}$ and $L_{1}$ are the constant-only and full model log likelihoods respectively. Significant coefficients are indicated by $*, * *, * * *$, for significance at the 10,5 and $1 \%$ level, respectively. All estimations include a constant. Estimations (1), (3), and (5) also include dummy variables for high and low lands. See main text for the independent variable definitions. Dependent variables are defined as follows: $\nabla\left(Y_{r} / Y\right)>0$ : Dependent variable takes value 1 if county $r$ increased its share in total production, 0 otherwise. $\nabla I_{r}>0$ : Dependent variable takes value 1 if county $r$ increased its regional specialisation index, 0 otherwise. $\nabla \ddot{I}_{r f}>0$ : Dependent variable takes value 1 if county $r$ increased its within-county farm specialisation index, 0 otherwise.

weighted by county crop shares of the first period, $t=1979: 1983$, then the contribution of within-county specialisation is negative. When the weights correspond to the last period, the sign reverses. These results corroborate conclusions from the decomposition presented in Table 2. There is growing specialisation because of an increase in regional specialisation and not because of an increase in within-county specialisation. In addition, counties with initially high specialisation values have increased their importance in national output.

In order to study the sources of specialisation change, dummy variables for positive changes in $\nabla I_{r}, \nabla \ddot{I}_{r f}$ and $\nabla\left(Y_{r} / Y\right)$ are calculated. Then probit estimations are carried out to analyse the effects of $E P, S P, S A, N F P P$, and $S F$ on these dummy variables. ${ }^{13}$

The results are presented in Table 4. Two variable specifications for each equation are reported. The first one includes all the variables whilst in the second one only those variables that are significant in at least one equation are used. The results show the estimated average change in the probability of the dependent variable for an infinitesimal change in each independent variable. In the first two columns, the probit results for the change in the county's weight in the national sector, $\nabla\left(Y_{r} / Y\right)$ are presented. A positive sign in a coefficient indicates that an increase in the related variable is associated with positive changes in the county's share in national production. The findings suggest that

13 Other specifications were also estimated. Linear regressions of the changes in the indices led to qualitatively similar results but the coefficients were not estimated with accuracy. An ordered probit model with four categories for the dependent variables improved the accuracy of the estimates with respect to the linear regressions but were still less satisfactory than the simpler probit specification. A closer inspection of the distribution of the dependent variables and the regressors highlighted the existence of many near-zero values in the latter. Plots of the dependent variables against the regressors suggested the existence of thresholds and nonlinearities in the data set. The probit specification works reasonably well because it provides a flexible treatment for the non-linearity problem and, at the same time, fully exploits the signs of the changes without adding noise. 
those counties with initial specialisation in strongly supported products and cereals have diminished their shares in national output.

Between-county specialisation results are presented in columns 3 and 4 . By far the most important and significant factor is initial specialisation in export-oriented crops. The percentage of land used in cereal production also has a very significant and positive effect, but of somewhat lesser magnitude. This finding suggests that set-aside programs and compensatory payments in cereals have had a negative effect on the production of other crops. Estimates for within-county specialisation are presented in columns 5 and 6 . Neither the export's potential nor the subsidy propensity help explain the sign of the specialisation change. In contrast, the initial proportion of cereal land use is significant and positive, although the effect is only half the size of the one found for regional specialisation.

\section{Concluding remarks}

The multifunctional approach of the European Commission focuses on environmental and productive issues so that the analysis of the forces affecting specialisation trends is of great importance in evaluating the impact of the CAP. Using Spain as a case study, we show that integration in the European Union and implementation of the CAP has led to an increase in regional specialisation as opposed to farm-level specialisation within regions, and that regional specialisation has increased most in regions initially specialising in export-oriented products.

With respect to the CAP, our findings put into question the argument of multi functionality frequently used by the EU Commission whereby CAP interventions at regional level supposedly stabilize the structure of land use so as to help preserve landscape and rural areas and limit agricultural surpluses. First, regions initially specialised in CAP-protected crops have witnessed a decrease in the importance of their production at the national level, in spite of the large increases in support prices of their main crops. Second, regions which initially specialised in cereals experienced a significant increase in specialisation both at county and farm level, suggesting that the 1992 reforms related to set-aside programs for cereals had an unexpected negative effect on the production of other crops.

\section{Acknowledgements}

We acknowledge financial support from the Spanish Ministry of Agriculture, Project Number 680. We acknowledge financial support from DGI, Grant BEC 2000-0170 and SEC 1999-135E. We also wish to thank Carlos García Peñas for his invaluable assistance in the process of data gathering and José Eusebio de la Torre for his excellent research assistance.

\section{References}

Boisso, D.K., Hajeks, J.H., Silber, J., 1994. Occupational segregation in the multidimensional case. Journal of Econometrics 61, 161171. 
Capt, D., Schmitt, B., 2000. Economie spatiale et agriculture: Les dynamiques spatiales de l'agriculture contemporaine. Revue d'Economie Regionale et Urbaine 0 (3), 385406.

Desmet, K., Fafchamps, M., 2000. The changing spatial distribution of economic activity across U.S. counties. University of Oxford Department of Economics Discussion Paper 43.

Deutsch, J., Flückiger, Y., Silber, J., 1994. Measuring occupational segregation. Journal of Econometrics 61, 133146.

Engle, R.F., 1984. In: Griliches, Z., Intriligator, M.D. (Eds.), Handbook of Econometrics. Wald, likelihood ratio and Lagrange multiplier tests in econometrics, Vol. II. North-Holland, Amsterdam, pp. 775826.

Garcia Alvarez Coque, J.M., Castellano, E., Sancho, M., 1999. Los efectos redistributivos de la PAC y la cohesión, Un punto de vista mediterráneo,. Revista Asturiana de Economía 14, 5172.

Hanson, G.H., 1998. Market potential, increasing returns, and geographic concentration. National Bureau of Economic Research Working Paper 6429.

Hubbell, B.J., Welsh, R., 1998. An examination of trends in geographic concentration in U.S. hog production, 1974 96. Journal of Agricultural and Applied Economics 30 (2), 285299.

Jones, R.W., Neary, J.P., 1984. In: Jones, R.W., Kenen, P.B. (Eds.), Handbook of International Economics. The positive theory of international trade, Vol. I. North-Holland, Amsterdam, pp. 162.

MEH, 1979 1997. Estadísticas de Comercio Exterior. MEH, Madrid.

Messerlin, P., 2001. Measuring the Costs of Economic Protection in Europe. Institute for International Economics, Washington.

Mora, R., Ruiz-Castillo, J., 2000. Additively Decomposable Segregation Indexes. The Case of Gender Segregation by Occupations in Spain, Universidad Carlos III de Madrid Economic Series Working Paper 00-63.

Mora, R., San Juan, C., 2002. Efectos en la Oferta de las Regulaciones de Mercados: Un analisis por CCAA de la concentracion y segregacion productiva. In: de Espinosa, L. (Ed.), Visión del Futuro de la Agricultura Española. MAPA, Madrid, pp. 1345.

OECD, 1994, Agricultural Policies, Markets and Trade, OECD, Paris.

Overman, H.G., Redding, S., Venables, A.J., 2001. The economic geography of trade, production and income. A Survey of Empirics, Centre for Economic Policy Research Performance dp 2978.

Peterson, R.N., 1995. The concentration of agricultural production in Canada and the United States since 1970: An Ortega parameter analysis. Canadian Journal of Agricultural Economics, Special Issue: Farm, Farm Families and Farming Communities, pp. 4765.

Theil, H., Finizza, A.J., 1971. A note on the measurement of racial integration of schools by means of informational concepts. Journal of Mathematical Sociology 1, 187194.

Trefler, D., 1993. International factor price differences: Leontief was right!. Journal of Political Economy 101 (6), 961987.

Weyerbrock, S., 1998. Reform of the European Union's Common Agricultural Policy: How to reach GATTcompatibility? European Economic Review 42, 375411. 